\title{
ANALISIS STRATEGI PEMASARAN TABUNGAN MABRUR DI BANK SYARIAH MANDIRI KCP PANDAAN PASURUAN
}

\author{
Mauludianah, Moh. Mukhsinin Syu'aibi, Sukamto \\ diana01agustus@gmail.com, mukhsinin@yudharta.ac.id, \\ sukamto@yudharta.ac.id \\ Universitas Yudharta Pasuruan
}

\begin{abstract}
The Hajj is the fifth pillar of Islam that must be fulfilled by Muslims for those who are able to finance and physically. The waiting list for the Hajj pilgrimage in Indonesia can now reach 20 years or more, with it awakening many Muslims who then plan the Hajj from an early age by opening a Hajj and Umrah savings account at Bank Syariah Mandiri.

This study used qualitative research with primary data sources. Customers using Mabrur Savings products at Bank Syariah Mandiri Pandaan, Customer Service, Branch Operation Supervisor, Sales Force, other employees who served in Bank Syariah Mandiri KCP Pandaan. While secondary data sources come from books and other literature. Data collection techniques are carried out in 3 ways, namely: Observation, Interview and Documentation.

This study found that Marketing Mix in Mabrur Savings products, namely 1. Product Strategy: Based on sharia principles with mudharabah muthlaqah contract, competitive profit sharing based on the ratio determined by the bank, payments can be made using the ABATANA (auto debit) system from a savings account BSM for monthly deposits, the Validation Process is very fast and can be awaited, in collaboration with KBIH (Hajj Guidance Group) which is officially registered with the Department of Religion. 2. The Price Strategy consists of: a light initial deposit of IDR 100,000. 3. Strategy Place: The strategic location of Bank Syariah Mandiri with a minimalist yet modern design. 4. Strategy Promotion: Through websites, brochures, and various advertisements, Opening outlets or stands, Door to door, Bank Syariah Mandiri has an image as a Hajj Bank.
\end{abstract}

Keywords: Marketing Strategy, Mabrur Savings. 


\section{PENDAHULUAN}

Bank merupakan lembaga yang sangat dibutuhkan oleh masyarakat dan bukanlah suatu hal yang asing bagi masyarakat. Bank dianggap sebagai lembaga keuangan yang aman dalam melakukan berbagai macam aktivitas keuangan. Aktivitas keuangan yang sering dilakukan masyarakat seperti penyimpanan dana, peminjaman dana, investasi, maupun pengiriman uang dari satu tempat ke tempat yang lain. Bank merupakan lembaga keuangan yang sangat tergantung kepada kepercayaan dari nasabah yang menempatkan dana simpanannya pada bank. ${ }^{1}$

Salah satu tujuan dari berdirinya Bank Syariah adalah menghimpun dana dari masyarakat dalam bentuk tabungan dan memberikan bagi hasil kepada nasabahnya. Tabungan merupakan salah satu produk yang sangat banyak diminati oleh masyarakat. Banyak masyarakat yang ingin menyimpan dananya dalam bentuk tabungan, baik untuk tujuan masa yang akan datang ataupun jangka pendek. Bank Syariah Mandiri memiliki banyak produk tabungan seperti Tabungan BSM, Tabungan Investa Cendekia, Tabungan Mabrur, Tabungan Berencana, Tabungan Simpatik, Tabungan Pensiun dan lain-lain. Masing-masing dibuat untuk memenuhi kebutuhan nasabah sesuai dengan apa yang di inginkan. Salah satu tabungan yang banyak diminati masyarakat khusunya umat Islam adalah Tabungan Mabrur yang biasa dikenal dengan tabungan haji dan umrah. ${ }^{2}$

\section{KAJIAN TEORI}

\section{Pengertian Strategi}

Strategi berasal dari kata Yunani yaitu strategos (stratos: militer, agia: memimpin). Istilah strategi digunakan pertama kali pada dunia militer. Strategi yaitu seni pertempuran yang digunakan untuk memenangkan peperangan. Oleh karena itu, tidak heran jika istilah strategi sering sekali digunakan dalam kancah peperangan. Strategi juga menunjukkan arahan sebuah rencana besar dan rencana penting untuk mencapai suatu tujuan. ${ }^{3}$

\footnotetext{
${ }^{1}$ Syafii Antonio, Bank Syariah : Dari Teori Ke Praktek, (Jakarta : Gema Insani,2001), hlm 45.

${ }^{2}$ www.http://mandirisyariah.co.id

3 Heri Sudarsono, Bank dan Lembaga Keuangan Syariah : Deskripsi dan Literasi, (Yogyakarta : Ekonisia 2003), hlm 45.
}

..:::: Malia: Jurnal Ekonomi Islam, Volume 10 Nomor 2 Juni 2019 :::.. 
Strategi merupakan rencana jangka panjang yang terdiri atas aktivitas-aktivitas penting yang diperlukan untuk mencapai kinerja memuaskan yang sesuai dengan target Berdasarkan pengertian di atas, dapat disimpulkan bahwa strategi merupakan arahan umum yang dibuat oleh perusahaan untuk mencapai suatu tujuan yang sudah ditentukan. Strategi sangat penting bagi perusahaan karena dengan adanya strategi yang telah direncanakan akan mudah untuk mencapai suatu sasaran.

\section{Pengertian Pemasaran}

Pemasaran merupakan suatu proses kegiatan usaha untuk melaksanakan rencana-rencana yang diarahkan pada pemenuhan konsumen yang akan dipuaskan. Pemasaran juga dapat diartikan sebagai suatu kegiatan yang mengusahakan agar produk yang dipasarkan itu dapat diterima dan disenangi oleh pasar.

Pengertian pemasaran pada setiap perusahaan dapat dikatakan tidak ada perbedaan, hanya saja setiap perusahaan memiliki karakteristik tersendiri dalam hal penerapan pemasarannya. Misalnya, pemasaran pada suatu perusahaan yang menghasilkaan produk barang tertentu yang sangat berbeda dengan perusahaan yang bergerak pada bidang keuangan yang memiliki produk jasa.Bank sebagai suatu perusahaan yang bergerak dalam bidang keuangan dan produk yang diperjualbelikan oleh bank merupakan jasa keuangan.

Oleh karena itu, pemasaran pada dunia perbankan sedikit berbeda dengan perusahaan lainnya. Secara umum pengertian pemasaran bank yaitu suatu proses untuk menciptakan serta mempertukarkan produk dan jasa pada bank yang ditujukan untuk memenuhi kebutuhan dan keinginan dengan cara memberikan kepuasan kepada nasabah. ${ }^{4}$

\section{Bauran Pemasaran}

Bauran pemasaran merupakan sekumpulan alat pemasaran (marketing mix) yang sering digunakan oleh perusahaan untuk mencapai tujuan pemasarannya dalam pasar sasaran. Berdasarkan definisi tersebut dapat disimpulkan yang dimaksud dengan bauran pemasaran merupakan unsur-unsur terkait, diorganisir, dibaurkan dan digunakan dengan tepat

\footnotetext{
${ }^{4}$ Kasmir, Pemasaran Bank (Edisi Revisi), (Depok : Kencana Prenada, 2010), hlm 55.
} ..:::: Malia: Jurnal Ekonomi Islam, Volume 10 Nomor 2 Juni 2019 :::.. 
agar perusahaan dapat mencapai tujuan pemasaran dengan efektif dan memuaskan kebutuhan serta keinginan konsumen.

Setiap bank perlu mengelola kegiatan pemasarannya dengan baik untuk menjangkau pasar sasaran.Konsep bauran pemasaran sangat diperlukan pada setiap bank dalam mengelola kegiatan pemasarannya yang bertujuan untuk menjangkau pasar sasaran. Konsep bauran pemasaran itu sendiri terdiri dari 4P, yaitu product (produk), price (harga), place (tempat/lokasi) dan promotion (promosi). ${ }^{5}$

Konsep bauran pemasaran yang terdiri dari $4 \mathrm{P}$ yakni:

a. Product (produk)

Produk adalah sekumpulan nilai kepuasan yang kompleks. Nilai sebuah produk ditetapkan oleh pembeli berdasarkan manfaat yang akan mereka terima dari produk tersebut. Misal dengan melihat variasi produk, kualitas, desain, kemasan, ukuran, garansi dan lainlain.

b. Price (harga)

Penetapan harga harus dipertimbangkan dengan baik karena harga menentukan pendapatan suatu usaha/bisnis. Harga yang tidak tepat akan berakibat tidak menarik para pembeli untuk membeli barang tersebut. Beberapa dasar penetapan harga seperti biaya, konsumen dan persaingan sangat berpengaruh terhadap keputusan dalam menentukan harga. Jadi, untuk menentukan harga harus sesuai dengan strategi pemasaran secara keseluruhan.

c. Place (tempat/lokasi)

Lokasi memerlukan pertimbangan yang cermat terhadap beberapa faktor seperti akses misalnya lokasi yang mudah dijangkau sarana transportasi umum, visibilitas misalnya lokasi yang dapat dilihat dengan jelas dari tepi jalan, lalu lintas misalnya banyaknya orang yang berlalu lalang dapat memberikan peluang besar terjadinya pembelian, dan lain-lain.

d. Promotion (promosi)

Promosi merupakan salah satu faktor paling penentu keberhasilan suatu program pemasaran. Menurut Alma, promosi adalah suatu bentuk komunikasi pemasaran yang merupakan aktivitas

\footnotetext{
${ }^{5}$ R Hurriyati, Bauran Pemasaran dan Loyalitas Konsumen ,(Bandung : Alfabeta, 2005), hlm 48 .
}

..::: Malia: Jurnal Ekonomi Islam, Volume 10 Nomor 2 Juni 2019 :::.. 
pemasaran yang berusaha menyebarkan informasi, mempengaruhi/membujuk, dan/atau mengingatkan pasar sasaran atas perusahaan dan produknya agar bersedia menerima, membeli dan loyal pada produk yang ditawarkan perusahaan yang bersangkutan. Promosi mencakup promosi penjualan, periklanan, personal selling, sales promotion, word of mouth, dan publicity.

\section{Pengertian Bank Syariah}

Bank syariah merupakan lembaga keuangan yang berfungsi sebagai perantara bagi pihak yang kelebihan dana dengan pihak yang kekurangan dana untuk kegiatan usaha ataupun kegiatan lainnya yang sesuai dengan hukum Islam. Bank syariah biasa disebut Islamic banking yaitu suatu sistem perbankan dalam pelaksanaan operasionalnya tidak menggunakan sistem bunga (riba), spekulasi (maisir), dan ketidakpastian atau ketidakjelasan (gharar). Menurut Undang-Undang Perbankan Syariah No.21 Tahun 2008 menyatakan bahwa perbankan syariah adalah segala sesuatu yang menyangkut tentang Bank Syariah dan Unit Usaha Syariah, mencakup kelembagaan, kegiatan usaha, serta cara dan proses dalam melaksanakan kegiatan usahanya. ${ }^{6}$

Bank Syariah merupakan bank yang menjalankan kegiatan usahanya berdasarkan prinsip syariah dan menurut jenisnya terdiri atas Bank Umum Syariah (BUS), Unit Usaha Syariah (UUS), dan Bank Pembiayaan Rakyat Syariah (BPRS). Hubungan antara Bank dengan nasabah pada Bank Syariah bukan hubungan debitur dan kreditur, melainkan hubungan kemitraan (partnership) antara penyandang dana (shohibul maal) dan pengelola dana (mudharib). Oleh karena itu, tingkat laba bank syariah tidak hanya berpegaruh terhadap tingkat bagi hasil untuk para pemegang saham tetapi juga berpengaruh terhadap bagi hasil yang dapat diberikan kepada nasabah penyimpan dana.

\section{Produk Pendanaan Bank Syariah Mandiri ${ }^{7}$}

a. BSM Giro

1) Definisi

\footnotetext{
${ }^{6}$ Heri Sudarsono, Bank dan Lembaga Keuangan Syariah : Deskripsi dan Literasi, (Yogyakarta : Ekonisia 2003), hlm 45.

${ }^{7}$ Wawancara dengan costumer service
}

..:::: Malia: Jurnal Ekonomi Islam, Volume 10 Nomor 2 Juni 2019 :::.. 
Sarana penyimpanan dana dalam mata uang rupiah untuk kemudahan transaksi dengan pengelolaan berdasarkan prinsip wadiah yad dhamanah.

2) Manfaat

a) Dana aman dan tersedia setiap saat.

b) Kemudahan transaksi dengan menggunakan cek atau B/G.

c) Fasilitas Intercity Clearing untuk kecepatan bayar inkaso.

d) Fasilitas BSM Card, sebagai kartu ATM sekaligus debet (untuk perorangan).

e) Fasilitas pengiriman account statement setiap awala bulan.

f) Bonus bulanan yang diberikan sesuai dengan kebijakan BSM.

3) Persyaratan

a) Perorangan : KTP/SIM/Paspor nasabah.

b) Perusahaan : KTP Pengurus, Akte pendirian, SIUP, \& NPWP.

4) Karakteristik

a) Berdasarkan prinsip syariah dengan akad wadiah yad dhamanah.

b) Setoran awal dan saldo minimum Rp 500.000 (perorangan) dan Rp 1.000.000 (perusahaan).

c) Biaya administrasi bulanan untuk perorangan Rp15.000, sedangkan untuk perusahaan Rp25.000,-

d) Biaya tutup rekening Rp20.000.

e) Biaya adaministrasi buku cek/BG Rp100.000.

b. Tabungan BSM

1) Definisi

Tabungan dalam mata uang rupiah yang penarikan dan setorannya dapat dilakukan setiap saat selama jam kas dibuka di konter BSM atau melalui ATM.

2) Manfaat

a) Aman dan terjamin.

b) Online di selutuh outlet BSM.

c) Bagi hasil yang kompetitif.

d) Fasilitas BSM Card yang berfungsi sebagai kartu ATM dan debit.

e) Fasilitas e-Banking.

f) Kemudahan dalam penyaluran zakat, infaq dan sedekah. 
3) Persyaratan

Kartu identitas (KTP/SIM, Paspor) nasabah

4) Karakteristik

a) Berdasarkan prinsip syariah dengan akad mudharabah muthlaqoh.

b) Minimum setoran awal : Rp80.000.

c) Minimum setoran berikutnya : Rp10.000.

d) Saldo minimum : Rp50.000.

e) Biaya tutup rekening : Rp20.000.

f) Biaya administrasi/bulan : Rp10.000.

g) Bagi hasil sebesar : $15 \%$

5) Contoh perhitungan

Saldo rata-rata tabungan Pak hilmi bulan oktober 2010 adalah Rp1juta. Perbandingan bagi hasil (nisbah) antara Bank dan Nasabah adalah 66 : 34 bila saldo rata-rata tabungan seluruh nasabah BSM pada bulan Oktober adalah 70 milyar dan pendapatan Bank yang dibagihasilkan untuk nasabah tabungan adalah Rp6 milyar yang maka bagi hasil yang diperoleh pak hilmi adalah $=$

Rp 1.000.000 x Rp 6.000.000.000,- x15\% = Rp. 12.857,14 (sebelum dipotong pajak) Rp 70.000.000.

c. Tabungan Simpatik

1) Definisi

Tabungan berdasarkan prinsip wadiah yang penarikannya dapat dilakukan setiap saat berdasarkan syarat dan ketentuan.

2) Manfaat

a) Aman dan terjamin.

b) Online di seluruh outlite BSM.

c) Bonus yang diberikan setiap bulan sesuai dengan kebijakan BSM.

d) Fasilitas BSM Card, yang berfungsi sebagai kartu ATM dan Debit.

e) Fasilitas BSM Mobile Banking dan Net Banking.

f) Penyaluran zakat, infaq dan sedekah.

3) Persyaratan

Kartu identitas (KTP/SIM/Paspor) nasabah. 
$244\}\{$ Analisis Strategi Pemasaran Tabungan Mabrur

4) Karakteristik

a) Berdasarkan prinsip syariah dengan akad wadiah

b) Setoran awal minimal Rp20.000 (tanpa ATM) \& Rp30.000 (dengan ATM).

c) Setoran berikutnya minimal Rp10.000.

d) Saldo minimal Rp20.000 (tanpa ATM) \& Rp50.000 (dengan ATM).

e) Biaya tutup rekening Rp10.000.

f) Biaya administrasi Rp2.500 per rekening perbulan atau sebesar bonus bulanan (tidak mengurangi saldo minimal).

d. Tabungan Berencana

1) Definisi

Tabungan berjangka yang memberikan nisbah bagi hasil berjenjang serta kepastian pencapaian target dana yang telah ditetapkan.

2) Manfaat Tabungan
a) Bagi hasil yang kompetitif
b) Kemudahan perencanaan keuangan nasabah jangka panjang
c) Perlindungan asuransi secara gratis dan otomatis.
d) Jaminan pencapaian target dana.

3) Manfaat Asuransi

Santunan tunai berfungsi untuk memenuhi kekurangan target dana, sehingga manfaat asuransi dihitung dengan cara : Target dana-saldo saat klaim.

4) Persyaratan

a) Kartu identitas (KTP/SIM/Paspor) nasabah.

b) Memiliki Tabungan BSM sebagai rekening asal (source account).

5) Karakteristik

a) Berdasarkan prinsip syariah mudharabah muthlaqah.

b) Periode tabungan $1 \mathrm{~s} / \mathrm{d} 10$ tahun.

c) Usia nasabah minimal 18 tahun dan maksimal 60 tahun saat jatuh tempo.

d) Setoran bulanan minimal Rp100.000.

e) Target dana minimal Rp1.200.000 dan maksimal Rp200 juta.

f) Jumlah setoran bulanan dan periode tabungan tidak dapat diubah. 
g) Tidak dapat menerima setoran diluar setoran bulanan.

h) Saldo tabungan tidak bisa ditarik. Apabila ditutup sebelum jatuh tempo (akhir masa kontrak) akan dikenakan biaya administrasi.

i) Bagi hasil sebesar $43 \%$.

e. Tabungan Investa Cendekia

1) Definisi

Tabungan berjangka untuk keperluan uang pendidikan dengan jumlah setoran bulanan tetap (installment)dan dilengkapi dengan perlindungan asuransi.

2) Manfaat

a) Bagi hasil yang kompetitif.

b) Kemudahan perencanaan keuangan masa depan, khususnya putra/i

c) Perlindungan asuransi (sesuai dengan kepesertaan asuransi).

f. Tabungan Pensiun

1) Definisi

Tabungan Pensiun adalah simpanan dalam mata uang rupiah berdasarkan prinsip mudharabah mutlaqah, yang penarikannya dapat dilakukan setiap saat berdasarkan syarat-syarat dan ketentuan yang disepakati. Produk ini merupakan hasil kerjasama Bank Syariah Mandiri dengan PT Taspen yang diperuntukkan bagi pensiunan pegawai negeri Indonesia.

2) Manfaat

a) Pembukaan rekening dapat dilakukan di seluruh jaringan Mandiri Syariah

b) Aman

c) Membantu pengelolaan keuangan nasabah

d) Bagi hasil bersaing

e) Biaya administrasi ringan

3) Persyaratan

a) Pensiunan dan calon pensiunan Pegawai Negeri Sipil, Pejabat Negara, Hakim, TNI, Polri.

b) Penerima tunjangan yang dibayarkan oleh PT Taspen. Yaitu: Veteran PKRI dan KNIP.

c) Fotokopi KTP. 
d) Membuka Tabungan Pensiun dengan Membawa Tabungan Pensiun beserta SK (Surat Keputusan) Pensiun ke kantor PT Taspen

e) Mengisi formulir mutasi kantor bayar di PT Taspen

4) Karakteristik

a) Dikelola dengan prinsip mudharabah mutlaqah

b) Bagi hasil bersaing

c) Petunjuk memindahkan pembayaran pensiun melalui Bank Syariah Mandiri.

g. TabunganKU

1) Definisi

Merupakan tabungan untuk perorangan dengan persyaratan mudah dan ringan yang diterbitkan secara bersama oleh bank-bank di Indonesia guna menumbuhkan budaya menabung dan meningkatkan kesejahteraan masyarakat.

2) Manfaat

a) Online di seluruh outlite BSM.

b) Bonus yang diberikan sesuai dengan kebijakan BSM.

3) Fasilitas

a) Fasilitas TabunganKu, yang berfungsi sebagai kartu ATM dan Debit.

b) Fasilitas E-Banking, yaitu BSM Mobile Banking dan Net Banking.

c) Penyaluran zakat, infaq dan sedekah.

4) Persyaratan

Kartu identitas (KTP/SIM/Paspor) nasabah.

5) Karakteristik

a) Berdasarkan akad wadiah yad dhamanah.

b) Bebas biaya administrasi rekening.

c) Biaya pemeliharaan Kartu TabunganKu Rp2.000.

d) Setoran awal minimum Rp20.000.000.

e) Setoran selanjutnya minimum Rp10.000.

f) Saldo minimum rekening (setelah penarikan) Rp20.000.

g) Biaya penutupan rekening atas permintaan nasabah Rp20.000.

h) Jumlah minimum penarikan Rp100.000 kecuali saat tutup rekening. 
h. BSM Deposito

1) Definisi

Investasi berjangka waktu tertentu dalam mata uang rupiah yang dikelola berdasarkan prinsip Mudharabah Muthlaqah.

2) Manfaat

a) Dana aman dan terjamin dan dikelola secara syariah.

b) Bagi hasil yang kompetitif

c) Dapat dijadikan jaminan pembiayaan.

d) Fasilitas Automatic Roll Over (ARO).

3) Persyaratan

a) Perorangan : KTP/SIM/Paspor nasabah.

b) Perusahaan : KTP Pengurus, Akte pendirian, SIUP, \& NPWP.

4) Karakteristik

a) Jangka waktu yang fleksibel : 1,3,6 dan 12 bulan.

b) Dicairkan pada saat jatuh tempo

c) Setoran awal minimum Rp2.000.000.

d) Biaya materai Rp6.000.

5) Contoh perhitungan bagi hasil

Deposito ibu Diana Rp 10 juta berjangka waktu 1 bulan. Perbandingan nisbah bank adalah 48\% 52\% . Bila total saldo semua deposan (1bulan) adalah Rp200 milyar dan bagi hasil yang dibagikan adalah Rp 3milyar. Bagi hasil yang didapat Ibu Diana adalah :

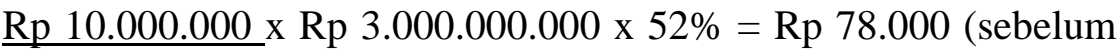
dipotong pajak) Rp200.000.000.

i. Tabungan Mabur

Tabungan berdasarkan prinsip wadiah yang penarikannya dapat dilakukan setiap saat berdasarkan syarat dan ketentuan. ${ }^{8}$

1) Mekanisme Tabungan Mabrur ${ }^{9}$

Secara garis besar alur atau mekanisme Tabungan Mabrur dari awal nasabah datang ke bank untuk membuka rekening sampai berangkat haji dan melakukan proses tutup tabungan adalah sebagai berikut:

a) Tahap membuka tabungan Mabrur sampai pendaftaran haji

\footnotetext{
${ }^{8}$ Wawancara dengan costumer service

${ }^{9}$ Wawancara dengan costumer service
}

...::: Malia: Jurnal Ekonomi Islam, Volume 10 Nomor 2 Juni 2019 :::... 
b) Nasabah membuka rekening dengan cara :

- Membuka rekening sendiri atau khusus Tabungan Mabrur

- Menggunakan sistem ABATANA (autodebet)

c) Membawa persyaratan Tabungan Mabrur kemudian Costumer Service memprosesnya

d) Setelah persyaratan terpenuhi kemudian proses Validasi, yaitu proses resmi menjadi nasabah Tabungan Mabrur dan berhak melakukan pelunasan biaya haji, jika di Bank Syariah Mandiri proses Validasi bisa di tunggu. Setelah proses Validasi dilakukan maka nasabah berhak:

- Melakukan proses pembayaran haji

- Mendapatkan lembar Validasi sebagai bukti

- Cetak lembar validasi

e) Pemorsian Ibadah Haji ke Departemen Agama dengan syarat :

- Saldo tabungan sebesar Rp25.100.000

- Membawa lembar validasi

- Foto Copy KTP

- Foto Copy Kartu Keluarga

- Surat nikah

- Surat Keterangan Sehat

- Foto 3x4 sebanyak 5 lembar

- Rekam sidik jari

- Mendapat cetak lembar porsi haji atau nomor antrian haji.

Dalam proses pengurusan untuk mendapatkan porsi haji, bank memberikan fasilitas pendampingan dari berbagai Kelompok Bimbingan Ibadah Haji dan Umrah $(\mathrm{KBIH})$ yang sudah resmi dan terjamin. Tergantung kepada nasabah ingin menggunakan fasilitas tersebut atau memilih mengurus segala prosesnya sendiri.

a) Tahap proses pelunasan biaya haji (menunggu nomor antrian)

Dalam tahap ini bank menawarkan kepada nasabah untuk melakukan proses pelunasan ibadah haji dengan:

- Membayar secara tunai kekurangan biaya ibadah haji

- Dengan system ABATANA (Autodebet) yaitu proses pemindahan saldo tabungan simpatik ke Tabungan Mabrur.

- Atau dari Tabungan Mabrur itu sendiri dengan system setoran selanjutnya. 
b) Tahap pelunasan

- Yang pertama adalah nasabah akan mendapat panggilan dari Departemen Agama tentang tahun keberangkatan (karena terkadang bisa lebih awal dari nomor antrian).

- Membawa lembar porsi pelunasan

- Kemudian dilakukan proses Manasik atau bimbingan haji

- Setelah jatuh tempo, nasabah akan berangkat Haji

c) Tahap penutupan rekening Tabungan Mabrur

Ada 3 cara yang bisa dilakukan nasabah untuk proses penutupan Tabungan Mabrur tentunya hal ini dilakukan setelah nasabah pulang dari ibadah Haji.

\section{METODE PENELITIAN}

Penelitian ini menggunakan penelitian kualitatif dengan Sumber data primer Nasabah pengguna produk Tabungan Mabrur di Bank Syariah Mandiri Pandaan, Customer Service di Bank Syariah Mandiri KCP Pandaan, Branch Operation Supervisor di Bank Syariah Mandiri KCP Pandaan, Sales Force di Bank Syariah Mandiri KCP Pandaan, Karyawan lain yang bertugas di Bank Syariah Mandiri KCP Pandaan. Sedangkan sumber data sekunder berasal dari buku-buku maupun literatur lain. Teknik pengumpulan data dilakukan dengan 3 cara yaitu : Observasi, Wawancara dan Dokumentasi.

\section{PEMBAHASAN}

\section{Strategi Pemasaran Tabungan Mabrur}

Strategi Pemasaran sangat diperlukan dalam menghadapi persaingan pasar pada sebuah lembaga keuangan salah satunya pada Bank Syariah mandiri. Bagi Bank Syariah Mandiri strategi pemasaran sangat penting untuk memperkenalkan produk-produk bank kepada masyarakat. Salah satu produk yang diperkenalkan Bank Syariah Mandiri adalah produk tabungan haji dan umrah yang biasa dikenal dengan produk Tabungan Mabrur. Produk Tabungan Mabrur merupakan salah satu produk unggulan Bank Syariah Mandiri yang diperuntukan bagi nasabah yang ingin melaksanakan ibadah haji dan umrah sehingga keinginannya dapat terpenuhi. ${ }^{10}$

\footnotetext{
${ }^{10}$ Wawancara dengan Costumer Service
} 
$250\}\{$ Analisis Strategi Pemasaran Tabungan Mabrur

Setiap melakukan kegiatan pemasaran, diperlukan bauran pemasaran atau marketing mix. Bank Syariah Mandiri memiliki beberapa strategi tersendiri dalam melakukan pemasarannya sebagai berikut:

1. Strategi Product

Produk merupakan hal penting yang perlu diperhatikan dalam strategi bauran pemasaran, karena tanpa adanya produk strategi bauran pemasaran lainnya tidak akan dapat dilakukan. Daftar tunggu haji di Indonesia yang terjadi pada saat ini yang mencapai 20 tahun bahkan lebih, menyadarkan umat muslim yang kemudian merencanakan ibadah haji sejak dini dengan cara membuka rekening tabungan haji. Hal ini kemudian menjadi peluang bagi bank syariah mandiri yang kemudian menciptakan produk tabungan haji dan umrah (Tabungan Mabrur) dengan berdasarkan akad mudharabah muthlaqah.

Strategi Product yang digunakan Bank Syariah Mandiri dalam menampilkan mutu dari produk Tabungan Mabrur tersebut sehingga dapat memenuhi kebutuhan dan keinginan segmen pasar, antara lain:

a. Berdasarkan prinsip syariah dengan akad mudharabah muthlaqah, yaitu system bagi hasil dimana nasabah memberikan kebebasan kepada bank untuk mengelola uang tersebut.

b. Bagi hasil yang kompetitif berdasarkan nisbah yang telah ditetapkan oleh bank.

c. Pembayaran dapat dilakukan dengan menggunakan sistem ABATANA (autodebet) dari rekening tabungan BSM untuk setoran bulanan.

d. Proses Validasi sangat cepat dan bisa ditunggu.

Bekerjasama dengan KBIH (Kelompok Bimbingan Ibadah Haji) yang resmi terdaftar di Departement Agama. Fungsi KBIH diantaranya:

a. Membantu proses administrasi bagi nasabah yang awam.

b. Bimbingan ibadah haji atau umrah.

c. Membantu Prosesnya sampai keberangkatan.

2. Strategi Price

Harga juga merupakan aspek penting dalam kegiatan marketing mix. Penentuan harga menjadi sangat penting untuk diperhatikan karena harga merupakan salah satu yang menentukan laku tidaknya produk pada perbankan. Salah dalam menentukan harga akan berakibat fatal terhadap produk yang akan ditawarkan. Bank harus menentukan harga dari produk dengan mempertimbangkan keuntungan yang didapat pula.

..::: Malia: Jurnal Ekonomi Islam, Volume 10 Nomor 2 Juni 2019 ::.... 
Bank Syariah Mandiri menetapkan harga yang ringan pada produk tabungan mabrur berdasarkan dengan keadaan dan kemampuan nasabah yaitu sebesar Rp100.000 untuk setoran awal.

Untuk ibadah umrah Bank Syariah Mandiri telah kerjasama travel umrah dengan harga yang bersaing dan kualitas terjamin. Diantaranya berupa promo khusus untuk nasabah berupa potongan harga (Rp 23.000.000 menjadi 22.000.000).

3. Strategi Place

Bank Syariah Mandiri KCP Pandaan terletak di lokasi yang sangat strategis bertempat di Pertokoan Niaga Blok A1, Jl Ahmad Yani No 321, Pandaan, Pasuruan, Jawa Timur. Jalan ini merupakan jalan yang cukup mudah ditempuh dengan kendaraan bermotor ataupun kendaraan-kendaraan lainnya, serta berada diantara ruko-ruko dan banyak berdiri bangunan bank, baik syariah maupun konvensional. Di samping dari pemilihan lokasi yang tepat, Bank Syariah Mandiri juga mendesain kantor di mana kantor merupakan tempat bertransaksi secara langsung dengan nasabah.

Bank mendesain kantor sesuai dengan perkembangan yaitu dengan konsep minimalis dan modern. Konsep modern dan minimalis dapat dilihat dari bentuk bangunan yang simpel tetapi tetap terlihat elegan. Desain ruangan yang simpel bisa membawa nuansa nyaman sehingga diharapkan nasabah dapat merasa nyaman dengan kondisi kantor seperti itu.

Selain melakukan transaksi di kantor, marketing Bank Syariah Mandiri juga bersedia dengan langsung mendatangi nasabah di rumah atau di tempat mereka berusaha karena nasabah akan merasa diringankan dan diuntungkan serta merasa puas atas pelayanan yang diberikan oleh bank. Selain itu ketika di luar kantor marketing bisa lebih leluasa dalam menjelaskan dan memasarkan produk banknya kepada calon nasabah.

4. Strategi Promotion

Promosi merupakan marketing mix yang terakhir. Kegiatan promosi ini merupakan kegiatan yang sama pentingnya dengan ketiga kegiatan di atas baik produk, harga maupun tempat. Promosi juga merupakan kegiatan yang paling ampuh untuk menarik nasabah serta 
$252\}$ Analisis Strategi Pemasaran Tabungan Mabrur

mempertahankan nasabah. ${ }^{11}$ Kegiatan promosi dapat dikatakan kegiatan yang paling efektif dilakukan karena marketing serta karyawan lainnya sudah terbiasa dalam memasarkan semua produknya baik di dalam kantor maupun di luar kantor. Berikut adalah strategi promosi yang dilakukan Bank Syariah Mandiri KCP Pandaan dalam mempromosikan produk Tabungan Mabrur:

a. Marketing menawarkan produk Tabungan Mabrur kepada calon nasabah, keluarga, pasangan serta teman-temannya

b. Costumer service juga menawarkan produk Tabungan Mabrur kepada nasabah dengan sikap yang baik dalam melayani serta memiliki pengetahuan yang cukup dari produk yang ditawarkan sehingga dapat memberikan penjelasan yang baik kepada nasabah.

c. Pelayanan yang memuaskan akan menjadi promosi efektif bagi bank karena nasabah tersebut dapat menyampaikan kepada kerabat, teman, keluarga bahkan orang lain mengenai pelayanan yang unggul terhadap bank, sehingga dapat membuat citra bank semakin meningkat.

d. Bank Syariah Mandiri juga memperkenalkan produk Tabungan Mabrur melalui iklan yang terdapat pada mesin ATM yang dimiliki bank dan menyebar brosur yang sudah dibuat semenarik mungkin dengan informasi yang singkat dan lengkap sehingga calon nasabah dapat mengetahui informasi produk Tabungan Mabrur.

e. Bank Syariah Mandiri juga menyediakan website yang berisi informasi tentang bank syariah mandiri dengan produk maupun jasa layanan khususnya produk Tabungan Mabrur.

f.Marketing Bank Syariah Mandiri juga melakukan personal selling dengan cara door to door serta datang ke acara kelompok pengajian. Jika ada kegiatan manasik haji, marketing serta karyawan bank lainnya membuat gerai di acara tersebut dengan tujuan memperkenalkan produk tabungan haji dan umrah kepada masyarakat sehingga dapat menarik minat masyarakat dalam menabung.

g. Bank Syariah Mandiri juga mengajak kerjasama mitra-mitra dan instansi yang terkait.

${ }^{11}$ Wawancara dengan Marketing

..::: Malia: Jurnal Ekonomi Islam, Volume 10 Nomor 2 Juni 2019 ::.... 


\section{Analisis Strategi Pemasaran Tabungan Mabrur}

Dari uraian strategi pemasaran diatas menunjukkan bahwa Bank Syariah Mandiri konsiten dalam memasarkan dan mempromosikan produk-produknya terutama Tabungan Mabrur. Namun, tidak menutup kemungkinan untuk terus memperbaiki diri demi tercapainya tujuan dan target. Diantara hasil dan pencapaian yang diperoleh antara lain :

1. Jumlah nasabah Tabungan Mabrur Bank Syariah Mandiri lebih banyak diantara Bank Syariah lainnya didorong oleh Image Bank Syariah Mandiri dikenal sebagai Bank Haji atau yang paling professional dan banyak diminati masyarakat unruk melakukan proses Haji dan Umrah.

2. Peraturan pemerintah Departemen Agama melarang Bank Konvensional untuk membuka Tabungan Haji dan umrah.

\section{KESIMPULAN}

Berdasarkan pembahasan yang telah dibuat mengenai Analisis strategi pemasaran pada produk Tabungan Mabrur (haji dan umrah) di Bank Syariah Mandiri KCP Pandaan, maka dapat diambil kesimpulan bahwa:

Strategi pemasaran yang dilakukan oleh Bank Syariah Mandiri KCP Pandaan khususnya dalam memasarkan produk Tabungan Mabrur, Bank mengembangkan marketing mix (bauran pemasaran) yang terdiri dari empat unsur yakni strategi produk, strategi harga, strategi tempat dan strategi promosi. Hal ini bertujuan untuk memperkenalkan produk kepada masyarakat dan menarik minat masyarakat pada produk Tabungan Mabrur.

\section{DAFTAR PUSTAKA}

Antonio, Syafii. 2001. Bank Syariah : Dari Teori Ke Praktek. Jakarta : Gema Insani.

Buku Bank Syariah Mandiri KCP Pandaan.

Jazuli, Imam. 2014. Buku Pintar Haji dan Umrah. Yogyakarta : Ar-Ruzz Media.

Kasmir. 2010. Pemasaran Bank (Edisi Revis). Depok : Kencana Prenada.

$\mathrm{R}$ Hurriyati. 2005. Bauran Pemasaran dan Loyalitas Konsumen. Bandung:Alfabeta.

Rasjid, Sulaiman. 2014. Fiqh Islam. Bandung : Sinar Baru Algensindo. Sudarsono, Heri. 2003. Bank dan Lembaga Keuangan Syariah : Deskripsi dan Literasi. Yogyakarta : Ekonisia. 
$254\}$ Analisis Strategi Pemasaran Tabungan Mabrur

Sugiyono. 2014. Metode Penelitian Kuantitatif, Kualitatif dan $R \& D$. Bandung : Al-Fabeta.

www.http://mandirisyariah.co.id (diakses tanggal 25 Februari 2019)

..::: Malia: Jurnal Ekonomi Islam, Volume 10 Nomor 2 Juni 2019 :::... 